ASR

3,1

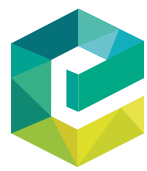

Annals in Social Responsibility Vol. 3 No. 1,2017 pp. $70-71$

(c) Emerald Publishing Limited 2056-3515

DOI 10.1108/ASR-10-2017-0011

\section{Educating the workforce through CSR}

\section{Corporate social responsibility as the key to coordinated workforce improvement}

In many sectors, there is a significant education gap between what people are being taught and what organizations need. These skills shortages are holding back industries as well as society. Corporate social responsibility (CSR) practices have the potential to change this situation. By adapting CSR to fit the educational needs of both current and future employees, organizations can simultaneously bridge the skills gap as well as improve employee loyalty and work ethic. Whilst the educational needs of society will continue to be the remit of government, businesses have the potential to help by getting involved with the direction of education for the future. The use of CSR programmes to improve education of employees and local talent is already being seen by some of the world's largest organizations.

The benefits of such an approach are considerable. Whilst the financial and resource costs would initially be high, the long-term potential for organizations to improve would justify this expense. Involving the private sector in education would be a win-win situation, with an improvement in the levels and funding of education available, and a larger and better trained talent pool. Additionally, improving inhouse education for current employees will promote loyalty and job retention. CSR is key here for both enhancing the view of an organization by its current employees, as well as attracting the best young talent. Furthermore, a strong CSR program could ensure that an organization uses any economic successes for societal gains and improvements.

\section{CSR's effects on human resources}

The most effective CSR strategies are those that have aligned an organization's purpose and values with social and environmental activities. By acting responsibly, an organization is able to reconfigure its core values and purposes to benefit society. Doing so can have the added benefit of improving relations between management and the larger body of employees. In the current employment climate, it is found that CSR can function better as an incentive to employees than financial rewards. Organizations are more attractive as an employer when they are seen to engage with charitable causes. This is even more prevalent in the youngest demographic of employees (both current and potential). Companies that engage with societal impact programmes are able to improve their reputation, making them attractive to prospective employees, and can dictate why people choose one organization over another. As such, pure financial performance is no longer the most important facet of an organization when it comes to employment. This has a knock-on effect with stakeholders, with corporate image improving with sustained and heightened CSR engagements.

The importance of CSR programmes, particularly those involving philanthropic or charitable causes, is that it builds a sense of corporate identification in the workforce. In fact, job performance is seen to improve in organizations with strong CSR programmes. Beyond this, CSR programmes are seen as making up part of an employee's value proposition: the benefits that an employee can expect in return for their job performance. Strength there greatly improves the retention of workers in an organization. When employees feel their employer shares their values, they are more likely to stay. Perks such as good work-life balance, flexible working, time off in emergencies, and maternity/paternity time off all demonstrate to employees that an organization has their best interests at the core of operations. Organizations are increasingly regarding employees not just as workers, but as people who have lives outside of work. 
This task is easier for large organizations, but is crucial for the survival of SMEs too, despite being harder for them. The key for all organizations is successful communication.

\section{The role of CSR in education}

The philanthropic dimension of CSR can be used in education to the benefit of both organizations and society. Corporations that direct funds into educational initiatives can improve their reputation, the loyalty of their employees, and increase their local talent pools. The benefits are universal, and particularly help younger generations cope with an increasingly competitive global employment market. There are numerous examples of such initiatives being a success. The New Employment Opportunities Initiative, made up of Walmart, Caterpillar, Microsoft, CEMEX, and MacDonald's, joined with the Inter-American Development Bank and the International Youth Foundation to train one million youths in Latin America and the Caribbean by 2022 . This initiative, funded with $\$ 37$ million from its founding partners, is already improving the prospects of the youngest generations, as well as increasing their own talent pools.

Cisco has done similar work, creating 10,000 networking academies across 165 countries. This programme has meant that 4.75 million people have improved their employability potential, and Cisco has increased and improved its talent pool globally. SAP and Verizon have similarly joined forces with local universities and education institutions to boost the education of STEM subjects. This has benefitted both the prospects of students as well as themselves. Intel Math and Intel Teach are comparable programmes offering training across the USA, aimed at addressing the perceived skill gap in technology and engineering. Intel has also committed funding to higher education for courses on microelectronics, nanotechnology, security systems, and entrepreneurship. SAP's initiative to employ people with autism in its technology-focused roles has led to their tapping of an under-explored talent market, whilst helping those with social difficulties who would be otherwise overlooked. In many instances, NGOs are crucial in the development and sustaining of connections between companies and governments for improving education.

Ultimately, the adoption of CSR practices can benefit both organizations, governments, and societies, utilizing the best of each sector. CSR programmes in corporations improve employee loyalty and job performance, which results in the improved financial performance of the employer. This in-turn means more money is able to be spent on CSR programmes. These programmes are able to improve the job prospects of younger generations when implemented in educational initiatives with the help of governments. The result is a reduction in unemployment, higher revenues for government, and a larger, better trained talent pool for corporations to hire from. The end result of CSR is that everyone becomes better off in some way.

\section{Comment}

The review is based on "Corporate sustainability and responsibility toward education" by Mark Anthony Camilleri (2017), published in the Journal of Global Responsibility.

\section{James Andrew Robertson}

\section{Reference}

Camilleri, M.A. (2017), “Corporate sustainability and responsibility toward education”, Journal of Global Responsibility, Vol. 7 No. 1, pp. 56-71.

\section{Educating the workforce through CSR}

